\title{
Study on Structure and Craft of Traditional Costumes of Edge
}

\author{
Fang Wang
}

\author{
ChangChun University of Technology, Jilin 130011, China
}

Keywords: Traditional costumes, structure of edge, craft of edge.

\begin{abstract}
Edge plays a requisite part of Chinese traditional costumes which is practical and decorative. It has gone through the process from the birth and the flourish to the deterioration. To study traditional costume culture does to the quintessence of fashion culture, which is the glorious duty to every practitioner of clothing culture. This article will interpret the edge of traditional cultural dress from quite a few angles, such as the notion, classification, structure and craft. We hope to provide valuable sources for individuals who enjoy Chinese traditional costume culture and contribute to the development of Chinese clothing culture.
\end{abstract}

\section{The basic concept of edge}

\subsection{What is the edge?}

Edge, is the edging of Chinese traditional dress and typical way of dealing with the clothes edge. It refers primarily to the off-line clothes place (such as the collar and cuffs, skirts, skirts, side vents, etc.) wrapped in the fabric and sewn up. That is not only beautiful and practical, but also improves the service life of the clothes greatly. In different historical periods, the structure and craft of the clothing edge which are ever-changing have different structural features and inner essence. To some extent, the edge is a kind of precipitation and expression of historical culture.

\subsection{The historical development of the edge.}

The development of the edge which has a long history can be traced to the same origin of the development of Chinese traditional costumes. As an important method for clothing treatment, it has gone through the process from the birth and the flourish to the deterioration. At first, the main operation of edge was "anti - silk which improved the wear resistance by sewing the edge of the cutting fabric. In the middle stage, the function of edge extended to "strengthening". It not only can make clothes more stable when wearing but also value its decorative role, and gradually begin to consider the color matching. In the mature period, the structure and craft of edge were more complex. The craft had also developed to a higher stage from the beginning to the stylized development. Due to various factors such as political and economic development, technological development, aesthetic style and artificial factors, edge gradually quoted the stage after a long stylized development.

\section{The basic classification of edge.}

Chinese clothing has a long history. In different periods, the style and name of clothing have changed greatly. Therefore, the call of edge was changed with it. Here in China Costume Dictionary which was written by Xun Zhou and Chunming Gao as a reference to introduce the edge classification

\subsection{The classification according to the location of edge.}

According to the documentation of Western Han Dynasty, the edge was break down into five main families 'Chun, Yuan, Zhuan, Biao, Ju'. Corresponding to today' garment structure it mainly means the parts of neckline, sleeves, skirt, hem, and refers to the place where the clothing is easy to 'gauze'. It is conceivable that the earliest function of edge is to improve the using of clothes.

\subsection{The classification according to the craft of edge.}

With the clothing culture developed rapidly, the edge technology is also constantly developing. The most typical of them is 'insert, inlay, and roll'. Archaeologists have found silk sash from the edge of costumes in warring state the Southern Song Dynasty, the clothes were set with exquisite colored 
edge. The craft of clothing was more complicated in the Qing Dynasty. Insert, inlay and roll had become the most common combination technology, and the color matching was also more diverse. The edge which had color, pattern, size, material had the effect that make the finishing point.

\subsection{The classification according to the edge of materials.}

During the Qin and Han Dynasties, the main materials of edge were silk fabrics, such as brocade, Juan, Luo and so on. It primarily focuses on the outline of clothing instead of the material.

Developing to the Sui and Tang dynasty, it began to edge by using the same material with clothes.

But in Qing Dynasty and the Republican period, it was more to use a very narrow margin, silk satin, silk cloth cable as the main material. In addition, it also commonly used edge materials such as silk ribbon (ribbon fabric) and show (the part of the fur).

\section{The research on structure of edge}

The yarn of edge fabric falls into vertical pleat (firm but has small elasticity), horizontal pleat and oblique yarn (elastic but waste material).

In the following part, we will focus on the edge modeling of vertical pleat and oblique yarn, and study the edge modeling in portrait so as to explore the different wisdom of the ancients in clothing production.

\subsection{The structure of edge in vertical pleat.}

From the Shang Dynasty, China had the edge culture. In The Shang Dynasty, jade and stone figure worn with edge decoration in the unearthed artifacts from Yinxu. Carving stone is not relatively clear from the texture. But it is usual to use the cemetery master image as mold and materials for jade. The carvings are clear and some are gorgeous. Having a variety of styles and designs, both sides of the clothes added up a narrow margin. From the point which the collar needs to be stable in the neck, this period belongs to the edge of vertical pleat.

The Qin Dynasty of the 3rd century B. C. united China in the spring and autumn period. To consolidate power, it followed some convention of the Warring States Period and made unified costumes. After Bang Liu established the Han Dynasty, most of the systems inherited the Qin Dynasty. In the part of dress, Emperor Wudi pursued to 'Ban from hundred philosophers, venerate Confucianism'. It is based on the fact of Confucianism, established new regulations and kept the traditional etiquette. As the first dress established country, the Han Dynasty clearly defined the edge such as width, width, material, color, pattern, which was a large extent affected the structure of the costumes. Because the clothing system is not perfect, the clothing structures of nobility were diversity. And the edge had the changes of width, thickness plain and splendor to achieve the best combination of practical and decorative.

In the period of the Sui and Tang Dynasties, the costumes of the cross collar, the lapel and the round collar also had the structure of the edge in vertical pleat. From the Southern and Northern dynasties onward, the contact between $\mathrm{Hu}$ and Han became more and more frequent. With the Xianbei costumes and the spread of Buddhism popularized, there were great change in Wai Jin and the Northern and Southern Dynasties. They were more elegant compared with the last one. For example, the cuffs were no longer tightening, and used more elegant fabric to reflect the pursuit of freedom. During the Tang Dynasty, the national who was rich and open promoted the trade with the neighboring countries. The fabric texture and color patterns were more changeable. There were strict rules for the formal clothing in edge color and pattern.

Over the long history, people of Qing dynasty wore symmetrical pieces clothing with solid edge. This is related to the living environment of the Manchu in the Qing Dynasty. Then, Nvzhen family lives in the area of Changbai Mountain, northeast of China. Because of the hunting lifestyles, clothing was mainly considering convenience of riding. Based the style on the gown which was connected, it was tight and narrow sleeves, closed and convenient for activities. After the founding of the Qing Dynasty, the clothing culture was influenced by the Han culture. From the tight to wide, the space of edge decoration was more and larger as well as the patterns were gradually enriching. 
Because of the many advantages, the edge of the vertical pleat had been reused in the development of Chinese clothing. It was not only simple when cutting edge but also saved the cloth. Due to the poor elasticity of the vertical pleat, it can play a good role in strengthening the edge, especially for the clothing material which is not the vertical pleat. But it is difficult to deal with the edge angle because of its poor elasticity. Therefore the vertical pleat was only used for the parts of cuffs, the full front of a Chinese gown and the lower hem.

\subsection{The structure of edge in oblique yarn.}

The edge of the gown is mostly made of vertical pleat, but some of them use oblique yarn. 'The 1st Chu tomb at Jiangling' is documented that N1 plain gauze is delivery, but the edge is oblique yarn. And the 'oblique yarn' - Ten' is known as 'oblique edge' in the 'Fei Zi Han which means not positive. But Chinese traditional fabric was cotton and silk, and made of solid pure cotton threads weaved together in crisscross. If clip by curve, it was easier to off line and waste material. Therefore, the ancient people mainly cut the fabric by 'straight line'. It not only embodies the philosophical viewpoint of saving and guiding but also makes scientific cutting according to the characteristics of the material. Because of its features, there is some extra fabric after cutting out. By using the extra fabric to the edge, it can form skew which show the effect of oblique yarn. And to use the oblique yarn in cross collar, that can provide some flexibility to be more comfortable.

There are two major types of the costumes with round collar, gown and blouse, which were a style of pursuing loose and comfortable. That was common in the costumes of $\mathrm{Hu}$ at first. During the Eastern Han Dynasty, Clothing of Han was affected and the gown with round collar began to appear. But in this period, the dress was generally used as lingerie, which would not turn the collar on both sides, and its edge form was similar to the style in the Sui and Tang Dynasties. However, there is no clothing relics unearthed that can not completely determine the association between the two dynasties. After the founding of the minority nationalities regime in Wei-Jin period, the minority becomes more significant that lay the foundation for the popularity of the late gowns. At first, the robe was worn as lingerie. But in the minority culture, the dress can be used as a garment and formal dress that reflected the popularity. After the Hu people entered the Central Plains, The culture of them was starting to affect the clothing culture of the Han people in the Central Plains. And the dress of the robe began to prevail. In some unearthed relics, archaeologists found a picture of that the Tibetan king sent out an envoy to visit Emperor Taizong, the robe worn by the envoy was long and mainly made up of yellow and red fabrics. The yellow cover most of the planet and red distributed at the marginal division, such as collar, front piece, cuffs as well as hem parts. That means that, red is actually the decoration of the edge in this picture. From the Song Dynasty, the robe began to prevail. It could be a casual dress or formal dress. And in order to dress comfortably, the neckline had gradually expanded. And from the craft of the circular collar, the collar edge solely to product in oblique yarn and sew to the clothes then.

'Chang' coat was popular in the Qing Dynasty and divided into waistcoat, gown, and jacket. The part of neckline and front piece were two individuals, completed by the edge decoration together after the process. It was known as 'Chang' because of the shape. The neckline of the clothing in the Qing Dynasty is an arc. According to the previous analysis of the characteristics of vertical pleat and oblique yarn, we know that the edge of the oblique yarn would be used here. Of course, through a large number of Qing Dynasty clothing, the edge modeling is generally concentrated in the collar. Because it was the center position that can foil the face. At the same time, this kind of clothing had big space and need stabilize through the decoration of the neckline. Therefore, the edge of collar was the core of all edges.

The Republican period was summit stages of Chinese traditional costumes, and it was also an important stage of the transition of the modern culture. The traditional culture had an encounter with fashion culture. The cheongsam is a typical representative. By Advocating simple, the edge culture got out from the late Qing Dynasty. The edge of this period is basically made of slanted silk strips whose edge is simple and the details are more beautiful. From the edge of some classic cheongsam, it can be analyzed that the change of edge modeling will follow the cheongsam's color, material, width 
and quantity. That not only valued difference collocation of color, but also paid attention to the collocation of texture.

\section{Research on the craft of edge}

The craft of edge could roughly divide into single and multi-layer. The function of them was to fix the edge of clothing and improve the abrasion of the clothes. The single edge which appeared early had more practical applicable value. The production process of that was relatively simple and could be used in many parts of the clothing. Although the lace had many colors, it covered in the clothing. So those actually belonged to a single edge. The multi-layer was compounded by two or several layer of fabric with rich colors and various combinations. And it was usual to use in edge.

\subsection{The craft of single edge.}

The craft of single edge contained a group of crafts, such as technology of the seam, technology of the band and technology of cropping. The sewing refers primarily to fold the edge of the vertical pleat, Turn the both sides inward, and be sutured with different acupuncture. From Qin-Han to Ming-Qing Dynasties and the Republican Period, the robe had been used. The main difference of edge was blind stitching, and it was mainly used in the part of clothing or cuffs. It was mainly decorative as well as strengthened the outline.

\subsection{The craft of multi-layer edge.}

There are two major types of the multi-layer edge, planar arrangement (such as splicing and edge piping) and multi dimensions (such as roll, insert and inlay).

In the planar arrangement, the stitching process is dominated by large surface and stitching the linear edge and the vertical pleat. This is in accordance with Tailor method of Chinese textiles. The function of fixation and decoration is obvious. The craft of the edge focused on detail decoration and used various ways to create. From Qin Dynasty and Han Dynasty till Manchu Dynasty last years, this process was the most highly regarded.

The stereo superpose is edge of combined process with various ways. It was mostly for details in cuffs, hem skirts and so on. Different combined process can reflect the different edge characteristics, such as the craft of emphasizing the role of molding, the craft of three-dimensional superposition covered, and the craft of edge in the shirt corners.

A number of ethnic minorities has the rich costume culture. Decorative edge will use embroidery techniques, stitching and molding process. For example, as Miao and Buyi nationality, their costumes color was mostly for dark color, which not only can highlight the decorative technology value of edge but also express their unique understanding of life and pray for good.

\section{Summary}

In Chinese traditional clothing culture, edge is the top priority of decoration. It not only has the functional and decorative function but also represents social status in many dynasties. The structure of edge as well as the direction and the width of the yarn go hand in hand. Meanwhile it has a direct relationship with the craft of edge. Understanding is the basis of inheritance. Hope this article can mean something to the development of modern clothing. Chinese costumes culture can absorb the essence of the traditional culture and carry forward the outstanding Chinese national cultural tradition.

\section{References}

[1] Xun Zhou, Chunming Gao. Dictionary of Chinese Costumes [M]. Shanghai: Shanghai Lexicographic Publishing House. 1996

[2] Mei Hua. Costumes and Chinese Culture. [M]. Beijing: People's Publishing House. 2001

[3] Zhuqiao Shen. Technology of Cheongsam [M]. Taipei: Shuangda Publishing House.1986. 
[4] Meng Zhou. The Comparative Study of Female Costumes Culture in Qiandongnan Miao and Dong Autonomous Prefecture [M]. Beijing: China Social Sciences Publishing House. 2012

[5] Ying Zhou. The Art on Finger---Study on the Traditional Costumes of the Minority Nationalities [M]. Beijing: China Books Publishing House. 2013

[6] Tomoko Torimaru. One Needle, One Thread: The Craft of Miao' s Costume in Guizhou [M]. Beijing: Beijing Textile Publishing House. 2011 